\title{
A Study on Reducing the Sleeping in Class Phenomenon in Japanese Universities through Student Motivation
}

\author{
Kei Mihara $^{1}$ \\ ${ }^{1}$ Faculty of Science and Engineering, Kindai University, Japan \\ Correspondence: Kei Mihara, Faculty of Science and Engineering, Kindai University, Japan.
}

Received: April 16, 2018

Accepted: May 10, 2018

Online Published: May 18, 2018

doi:10.5430/ijhe.v7n3p79

URL: https://doi.org/10.5430/ijhe.v7n3p79

\begin{abstract}
Falling asleep in class is a common phenomenon among students in Japanese universities. There are several possible reasons for this: tiredness from daily routine such as commuting, difficulty concentrating in 90-minute classes, or simply a lack of motivation to study. In the English as a foreign language (EFL) classes, university students are usually not as motivated as high school students, considering that English education in Japan is generally aimed at preparing students for university entrance examinations. This study, therefore, aimed mainly to examine ways to prevent students from falling asleep in class by improving their motivation levels. Based on the results of questionnaire surveys and focus group interviews, it sought to identify ways in which student attention and alertness in class can be improved. The participants in this study were asked to take a vocabulary test in class before completing exercises in their textbook. After four weeks, follow-up research was conducted using questionnaires and semi-structured interviews. The study results showed that taking a vocabulary test at the beginning of class was an effective method of motivating students; however, this alone did not prevent university students from falling asleep in class.
\end{abstract}

Keywords: falling asleep in class, student fatigue, language learning, concentration, motivational strategies, vocabulary tests

\section{Introduction}

\subsection{Introduce the Problem}

Falling asleep in class is a major problem in Japanese universities, especially in English as a foreign language (EFL) classes. There are several plausible reasons for this phenomenon. First, it could be attributed to students being tired after longer commute times than when they were in high school. In Japan, two-hour commutes are not uncommon for university students while the typical commute for high school students is usually less than an hour. Second, students may find it difficult to concentrate in lecture-style classes for 90 minutes, as it is a significant increase from the 50-minute classes in high school. A third plausible reason for Japanese university students' tendency to sleep in EFL classes might be a lack of motivation to study English on entering university. English education in Japan is generally aimed at preparing students for university entrance examinations and high school students must study English hard to enter university. Once admitted to a university, however, they no longer need to prepare for entrance examinations and thereby, first-year students, especially, are not motivated to learn English.

\subsection{Explore Solutions to the Problem}

Rapid globalization has led to Japan's Ministry of Education, Culture, Sports, Science and Technology (MEXT) encouraging Japanese universities in recent times to introduce "English as a Medium of Instruction." They want universities to provide classes taught in English to resolutely proceed with internationalization (Dearden, 2014; MEXT, 2009; Rose \& McKinley, 2018). In response to such a trend, the falling asleep in class phenomenon in EFL classes should be resolved. As will be mentioned in the next section, previous research has suggested that falling asleep in class has a negative effect on students' academic performance. University students may not have to prepare for entrance examinations, but they still need to improve their English skills to be successful in the present era of globalization. Therefore, this study aimed to identify an effective method of motivating university students to study English and prevent them from falling asleep in class. With these aims, an experiment was conducted with first-year students with relatively high levels of English proficiency. 


\section{Literature Review}

In earlier studies, falling asleep in class has been investigated from several different perspectives. Several studies have been conducted on daytime sleepiness among university students. Oginska and Pokorski's (2006) study indicated that $50 \%$ of university students have problems with daytime sleepiness, compared with $36 \%$ of adolescents and adults. Hershner and Chervin (2014) mentioned that daytime sleepiness is a major global problem among university students and suggested several possible reasons for this. The first is a lack of adequate sleep. University students do not get enough sleep because they generally go to bed later and get up earlier than do high school students. The second is their frequent use of technology before going to bed. Using cellphones or computers prior to sleeping has been shown to be associated with daytime sleepiness. Hershner and Chervin (2014) suggested that such a phenomenon is likely to have a negative effect on students' academic performance. Quoting previous studies linking sleep and students' learning and memory, they stated that sleep deprivation may negatively impact learning and memory. Similar results were found by de Souza, de Sousa, Maia, and de Azevedo (2012). Using a questionnaire and a sleep diary to investigate 522 teenage students and 128 teachers in Brazil, the researchers found that partial sleep deprivation, poor sleep quality, and daytime sleepiness resulted in poorer student school performance and poorer teacher job performance (de Souza et al., 2012).

Administering a questionnaire to 1,640 (1,350 male and 290 female) medical undergraduate students, Lu, Fang, Shen, Wang, and Sun (2011) investigated the same problem of students in China and found that more than $90 \%$ of the students were prone to falling asleep in class. Their findings also showed that the most common reason for this was excessive fatigue (51.45\%), while less common reasons included academic dullness (18.4\%), unqualified teaching $(12.4 \%)$, stress $(8.5 \%)$, and failure to understand lecture contents (4.8\%). Based on these results, Lu et al. (2011) suggested measures such as cultivating study interests and implementing teaching reforms to reduce the falling asleep in class phenomenon.

Lu et al.'s (2011) suggestion to cultivate study interests and improve student motivation is applicable in the Japanese educational environment as well. Boo, Dörnyei, and Ryan (2015) examined publications that focused on second language (L2) motivation. They analyzed established journal articles and book chapters that were written in English and published between 2005 and 2014. The data revealed that the largest participant group consisted of university students, and that Chinese and Japanese were the two most studied nationalities. Boo et al. (2015) also indicated that research in Asia on student motivation was almost exclusively related to English learning, often in monolingual contexts like Japan.

Regarding Lu et al.'s (2011) second suggestion to implement teaching reforms, Gopang, Soomro, and Bughio (2015) conducted a focus group consisting of students of compulsory English classes at a university in Pakistan. The results showed that students were dissatisfied with the lecture-based method of teaching. One solution explored by Gopang et al. (2015) was the "provision of some rewards (prize, appreciation)" (p. 143). After the class, one of the participants commented that the class was "simply fantastic" but explained that this was "because I won the prize" (p. 144). Receiving a prize pleased this participant since it meant that she had the ability to win a competition. Therefore, offering a reward or an incentive to students might be an effective motivator to learn English as a compulsory subject, but it also depends on the type of reward. The Six C's of Motivation-strategies to increase motivation-include "consequences," which means that student motivation increases if they have a chance to display their work (Turner \& Paris, 1995). Such opportunities are believed to improve students' self-confidence and positive self-image.

A similar study was conducted by Waninge, Dörnyei, and de Bot (2014), who examined four students' motivation over a period of two weeks. The participants, aged 11 and 12, were chosen from among students in their first year of the highest level of Dutch secondary education. The results showed that there were considerable ups and downs in student motivation within a single classroom session of 45-50 minutes, although they observed a stable level of overall motivation. For example, they observed a surge in motivation in one of the participants toward the end of the class (after 40 minutes). The participant undertook a test 40 minutes after the commencement of the class and commented that he had done well on the test. This explained the sudden surge in his motivation level (Waninge et al., 2014). Based on the findings of the above-mentioned research, the present study aimed to identify solutions to the problem of falling asleep in university EFL classes using a vocabulary test to motivate students. The study was conducted after obtaining ethical approval. 


\section{Method}

\subsection{Participants}

The participants were 23 first-year students (20 males and three females) from the engineering department of a university in Japan. The students' ages ranged from 18 to 20, and they were all native speakers of Japanese. The experiment was conducted in a General English class consisting of a total of 27 students (four students did not participate in the study). Each class was of 90 minutes duration. This was a compulsory course for the students, and as the name suggests, the students were learning general English, which involved mainly listening to or reading texts on general topics. They were using a textbook published by a Japanese company. What they were learning from the textbook was not very different from what they had learned in high school. The participants had higher levels of English proficiency than other first-year students, since each class was formed based on the placement test that the students had taken upon entering the university. As I was their English instructor, I was familiar with their English proficiency levels. However, I had no information about their private lives: where they lived, how long it took them to commute to school, whether they had a part-time job, how many hours they slept a day, and so on. Of the 27 students, 23 agreed to participate in this study. The four students who chose not to take part in the experiment took the vocabulary tests in class as did the other students, although they did not participate in any of the questionnaires, focus groups, or semi-structured interviews. Their vocabulary test results did not affect any of the 27 students' final grades in any way.

\subsection{Instruments}

This study integrated qualitative and quantitative methods by using qualitative analysis to help interpret quantitative findings. Focus groups and semi-structured interviews were employed as qualitative methods to obtain further information on quantitative data collected by administering questionnaires. As both methods have merits and demerits, Chi (1997) stated that the "most conservative way to integrate quantitative and qualitative analysis is to use the qualitative data to help interpret the quantitative results" (p. 280). Therefore, the study was conducted using this conservative method.

First, two questionnaires were administered to collect information about the participants concerning their experience of falling asleep in class, their interest in learning English, and their opinion about the English curriculum. The questionnires were developed exclusively for this study, and therefore had never been administered before. Questionnaire 1 consisted of four questions, one of which was the topic of the study: students' experience of falling asleep in class. The other three were issues that had been discussed every time the English curriculum was reviewed and revised at the department. The curriculum had been revised three times while I was in the department. Questionnaire 2 was a follow-up one-item questionnaire to obtain approval from the participants to administer a vocabulary test in class. Based on the results of the questionnaires, a vocabulary test was administered in class. After two weeks, a focus group interview was conducted to modify the way of administering the tests if necessary. After another two weeks, a follow-up questionnaire and semi-structured interviews were conducted to assess the results of the four-week experiment. The pre- and post-questionnaires were administered anonymously, although the participants were asked to write their name on the answer sheet of the vocabulary test.

\subsection{Research Questions}

The following research questions were formulated for this study:

1) Does taking a vocabulary test at the beginning of class increase students' motivation?

2) If so, does it also help prevent students from falling asleep in class?

\section{Results}

\subsection{Questionnaires}

Two questionnaire surveys were conducted. Questionnaire 1, comprising four questions, was administered one month after the beginning of the school year. It aimed to collect information about the participants' experience of falling asleep in class, their interest level in learning English, and their opinion about the English curriculum. One week later, Questionnaire 2 was administered. It was a follow-up questionnaire that contained one item, and its purpose was to obtain participants' approval to try a potential solution to the problem of falling asleep in class. The results are as shown below.

\subsubsection{Questionnaire 1}

Question 1 was a yes/no question that asked, "Have you slept in class after entering university?" As Figure 1 shows, 
as many as 21 students (91.3\%) responded "Yes, I have slept in class." Only two students (8.7\%) answered "No, I have never slept in class." Nobody chose "Undecided." These results are consistent with Lu et al.'s (2011) findings. Their study revealed that more than $90 \%$ of the undergraduate students surveyed had fallen asleep in class (Lu et al., 2011).

Question 2 was an open-ended question that asked, "What English skills do you most want to improve?" As is shown in Figure 2, of the participants, 19 students (82.6\%) said that they were most interested in the Test of English for International Communication Listening and Reading Test (TOEIC ${ }^{R}$ L\&R, henceforth TOEIC L\&R). More than 80\% wanted to improve their listening and reading skills, which are tested on the TOEIC L\&R. On the other hand, three students (13\%) said that they wanted to learn the English used in movies, and one student (4.4\%) expressed interest in the Test of English as a Foreign Language $\left(\mathrm{TOEFL}^{\mathrm{R}}\right)$.

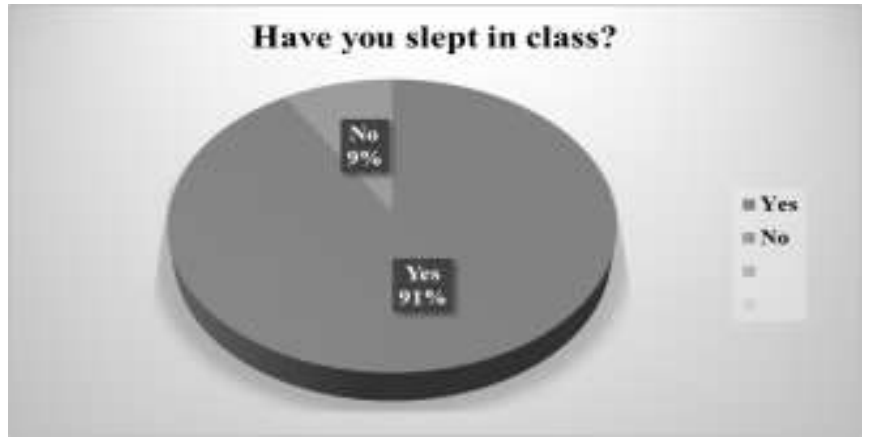

Figure 1. Have you slept in class after entering university?

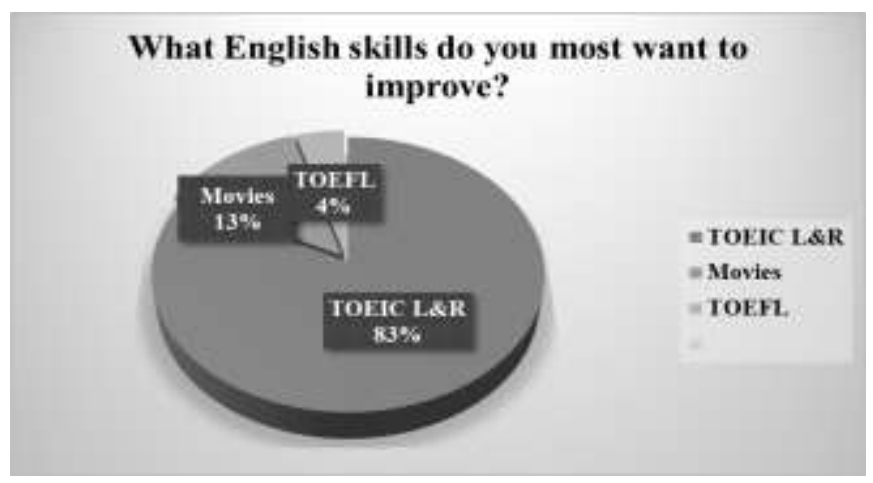

Figure 2. What English skills do you most want to improve?

Questions 3 and 4 asked about their opinion regarding the English curriculum. Question 3 asked, "Do you think the university should offer credits to students who achieve a score of 600 on the TOEIC L\&R?" As Figure 3 shows, all 23 students $(100.0 \%)$ responded "Yes." However, they seemed to have a different opinion about overseas English language programs.

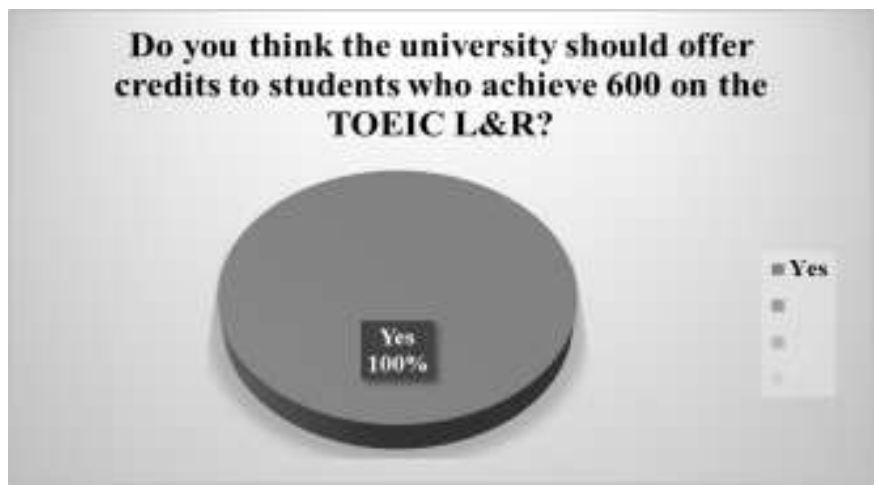

Figure 3. Do you think the university should offer credits to students who achieve a score of 600 on the TOEIC L\&R? 
Question 4 asked, "Do you think the university should offer credits to students who participate in a four-week overseas English language program?" As is shown in Figure 4, only 10 students (43.5\%) responded "Yes," while 13 students $(56.5 \%)$ responded "Undecided." The participants were later asked to provide additional information on this topic, and three male students voluntarily made comments detailing their personal opinions individually. They explained that achieving a high score on the TOEIC L\&R is different from joining an overseas English language program. One student said, "It is necessary to study very hard for the TOEIC L\&R, but participating in an overseas English language program does not necessarily require us to study hard. In fact, some participants may even skip classes to travel or go shopping!" Another student said, "Most of us can try the TOEIC L\&R because it is not very expensive to take the test. In contrast, it costs a fortune to participate in an overseas English language program, and not all of us can afford to join the program." They explained that students who successfully achieve a score of 600 on the TOEIC L\&R deserve some sort of "reward" for their efforts, such as university credits, although they believed that participants in an overseas English language program do not.

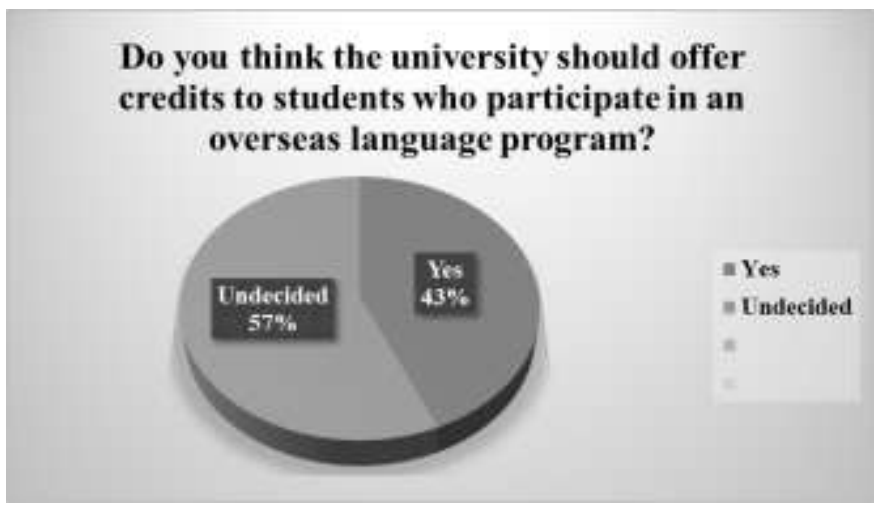

Figure 4. Do you think the university should offer credits to students who participate in a four-week overseas English language program?

\subsubsection{Questionnaire 2}

One week after Questionnaire 1, a one-item questionnaire was administered based on the results of the previous questionnaire. There was only one yes/no question on the questionnaire, which asked, "Do you want to take a vocabulary test to learn words and phrases commonly used in the TOEIC L\&R?" As Figure 5 shows, of the participants, 11 students (47.8\%) responded "Undecided." However, 12 students (52.2\%) responded "Yes, I want to take a vocabulary test." More importantly, none of them answered "No, I don't want to take a vocabulary test." Therefore, it was decided that the students were going to be given a test to memorize vocabulary items commonly used in the TOEIC L\&R.

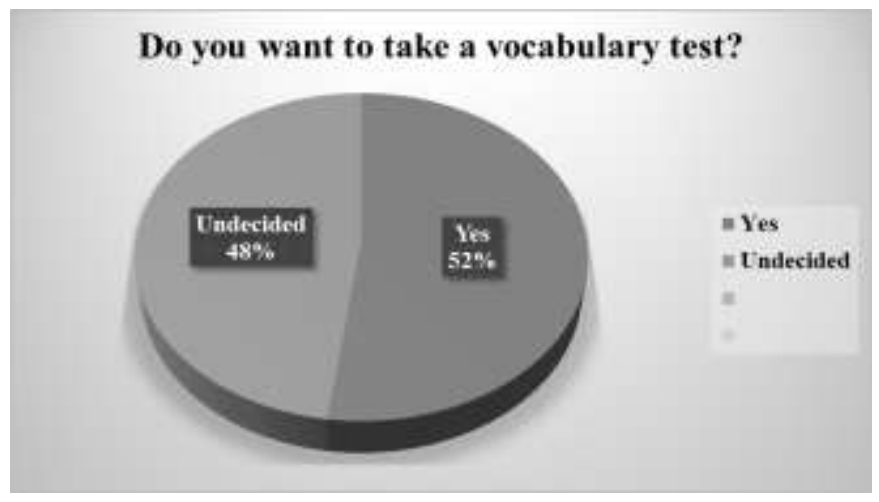

Figure 5. Do you want to take a vocabulary test to learn words and phrases commonly used in the TOEIC L\&R?

The TOEIC L\&R was created by the Educational Testing Service in the United States. It is one of the high-stakes tests in Japan, since many Japanese companies utilize applicants' and employees' TOEIC L\&R scores to make important decisions about hiring and promotions (The Institute for International Business Communication, 2007). 
Therefore, university students need a high TOEIC L\&R score to get a good job upon graduation. This test measures the English skills of people working in international workplaces, and targets the kinds of conversations, announcements, notices, and emails used in offices. The TOEIC L\&R is quite different from what students learn in high school, since high school students usually learn about environmental issues, cultural differences, or social issues in EFL classes.

In this experiment, the vocabulary tests were unrelated to the textbook they were using, and the test was administered at the beginning of class. As one of the participants in Waninge et al.'s (2014) study suddenly improved his motivation when he thought he did well on the test, the present study tried giving a test to the participants at the beginning of class to examine if this would increase their motivation for the rest of the class. As will be explained in the next section, the test took approximately 20 minutes, and when this was finished, the students started using their textbooks. Thus, it was hypothesized that if their motivation levels were high at 20 minutes into the class, it should be helpful for them to stay awake and concentrate on class activities.

\subsection{Vocabulary Tests and a Focus Group}

Two weeks before this experiment, the students were given four lists; each list consisted of 15 vocabulary items with their Japanese translations. The students were asked to memorize the meanings of these words. The lists were taken from a TOEIC wordbook written by my colleagues and published by a Japanese company. The students were given four lists because the experiment was conducted for four weeks. They were supposed to use one list per week. Every week, at the beginning of class, the students were given a test with 15 English vocabulary items, and they were required to write down the Japanese translations in the blanks. They were asked to mark their answer sheets themselves as soon as they finished the test. I collected their answer sheets, checked if they had marked the sheets correctly, and returned the sheets to the students during the next class. The students took approximately 15-20 minutes to take the test and mark their answer sheets. Therefore, I spent the first 20 minutes of class checking attendance and administering the test, and then I used the textbook for the remaining 70 minutes. After two weeks, a total of six students (four males and two females) participated in a focus group interview. I asked them when they preferred to take the TOEIC L\&R vocabulary test - at the beginning, in the middle, or near the end of class. They unanimously answered that they preferred to take the test at the beginning of class. One of them said, "Definitely at the beginning!" His statement was followed by others agreeing, some of them saying "Otherwise, I would be so worried about the test that I cannot concentrate on class." They also suggested changing the way of marking the answer sheets. Until this stage, the students had just been checking their answers - whether they had written the correct answer or not. However, from the next test, they were asked to write down the correct answer on their answer sheets if they had made a mistake or had not written anything. One of the six students who participated in the focus group interview said, "At first, I just marked my answer sheet. But when the teacher returned the sheet ... and when I saw that the teacher had written the correct answer for the vocabulary item whose meaning I did not write correctly, I thought it was a good idea. Just marking did not motivate me, but by writing the correct answer, I realized I had to memorize the vocabulary." The other five participants agreed that such a scoring method would probably improve their motivation to memorize the vocabulary items.

Two weeks after the focus group interview, a follow-up survey and semi-structured interviews were conducted to assess the results of the four-week experiment. The follow-up survey contained four multiple-choice questions and one open-ended question. It was administered to all the participants of this study. Then, three students participated in individual semi-structured interviews.

\subsection{Follow-up Survey}

One week after the experiment, a follow-up survey was conducted to obtain further information. A post-questionnaire was completed by all the study participants. It was a five-item questionnaire, which consisted of four multiple-choice questions and one open-ended question. One week after the post-questionnaire, semi-structured interviews were conducted with three students who had not taken part in the focus group interview. The results are discussed below.

\subsubsection{Post-Questionnaire}

Question 1 was the same question that was asked to the participants in the focus group interview. It asked, "When do you prefer to take the TOEIC L\&R vocabulary test? At the beginning, in the middle, or near the end of class?" As shown in Figure 6, all 23 students (100.0\%) chose "At the beginning of class."

Question 2 was a yes/no question, which asked, "Do you think you have enriched your vocabulary?" As Figure 7 shows, six students (26.1\%) responded "Yes," four students (17.4\%) responded "No," and 13 students (56.5\%) answered "Undecided." This means that more than half of the participants were not sure whether they had enriched 
their vocabulary or not. In this sense, they did not necessarily enjoy a feeling of accomplishment by taking the vocabulary tests.

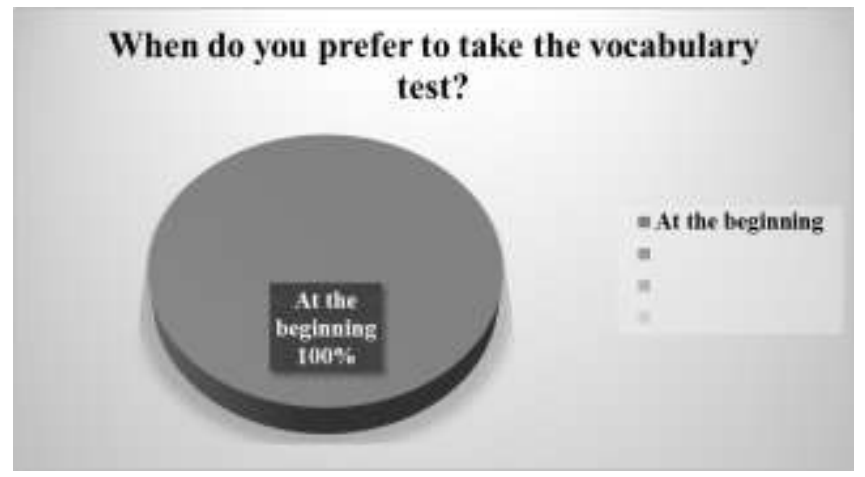

Figure 6. When do you prefer to take the TOEIC L\&R vocabulary test? At the beginning, in the middle, or near the end of class?

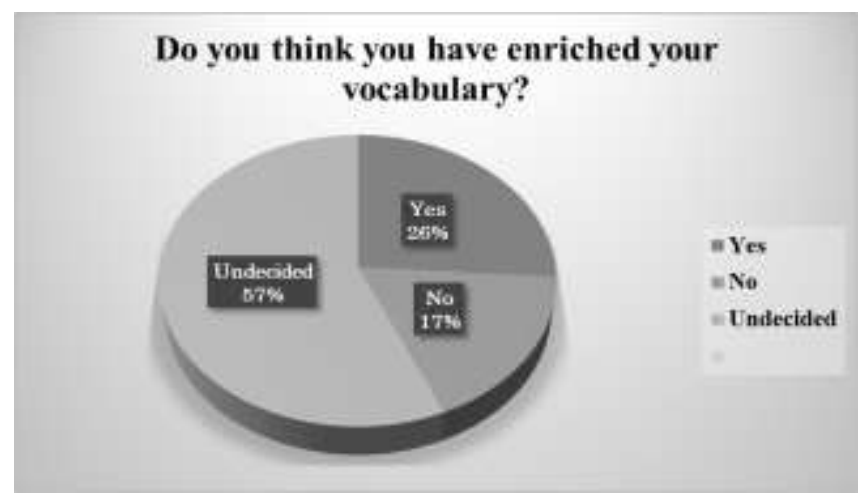

Figure 7. Do you think you have enriched your vocabulary?

However, their responses to Question 3, shown in Figure 8, seemed quite contradictory. This question was "Do you think taking the TOEIC L\&R vocabulary test has increased your motivation?" Seventeen students $(73.9 \%)$ answered "Yes," none (0.0\%) answered "No," and six students (26.1\%) responded "Undecided." Thus, more than 70\% of the participants responded that taking the vocabulary tests motivated them. Based on this result, it can be inferred that the vocabulary tests positively affected student motivation.

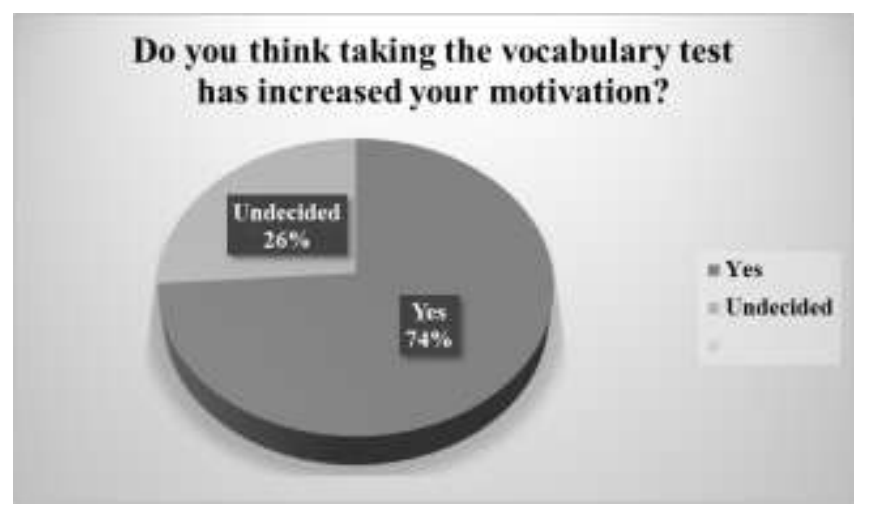

Figure 8. Do you think taking the TOEIC L\&R vocabulary test has increased your motivation?

Question 4 reflected the principal focus of this study. It asked, "Do you think taking the TOEIC L\&R vocabulary test helped to keep you awake in class?" As Figure 9 shows, as many as 21 students (91.3\%) responded "Undecided." Although none (0.0\%) answered "No," only two students (8.7\%) answered "Yes." The results of Questions 3 and 4 showed that the participants in this study improved their motivation by taking a vocabulary test at the beginning of 
class, but this was not motivation enough to prevent them from falling asleep in class.

Question 5 was an open-ended question, which asked, "How do you feel about taking a TOEIC L\&R vocabulary test at the beginning of class that is not related to the textbook?" There were both positive and negative responses to this question. Here are some interesting answers: "Learning the TOEIC L\&R vocabulary is useful," "The teacher should spend more time in helping her students to prepare for the TOEIC L\&R," "I found it tough because the TOEIC L\&R vocabulary is quite different from the vocabulary I learned in high school," "Sometimes I don't feel like studying, and it cannot be helped," "I don't think falling asleep in class has anything to do with taking a test or something like that," "Sometimes I am sleepy for no reason," and "I don't think the textbook is worth using, and therefore I would rather take TOEIC L\&R vocabulary tests."

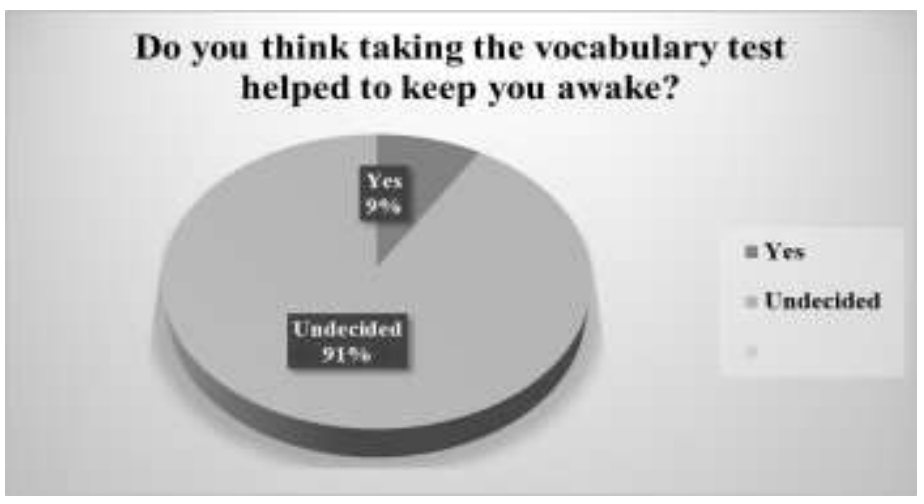

Figure 9. Do you think taking the TOEIC L\&R vocabulary test helped to keep you awake in class?

\subsubsection{Semi-Structured Interviews}

To obtain further information, semi-structured interviews were conducted with three students (two males and one female) who did not take part in the focus group interview. Each of the students participated in the interview separately, and it was found that the three interviewees had surprisingly similar opinions. Regarding Question 1 of the post-questionnaire, they said they preferred to take the test at the beginning of class. When they were asked the reason(s) for their preference, they referred to difficulties in concentrating on class activities. One interviewee said, "Taking a test in the middle or near the end of class would be simply disturbing." If they had been asked to take the test in the middle or near the end of class, they would have faced difficulties in concentrating on learning activities because they would have been too concerned about the test. This was exactly what one of the participants in the focus group interview said and was agreed on unanimously. Additionally, one semi-structured interviewee said, "For me, it was a sort of warm-up exercise. Therefore, I like to take a vocabulary test before working on exercises in the textbook." None of the participants in the focus group interview said anything other than difficulties in concentrating on class activities.

Regarding Question 2, they said they were not sure whether they had enriched their vocabulary, mainly because they had not actually taken the TOEIC L\&R yet. One interviewee said, "How can I know if I have enriched my vocabulary? I took a vocabulary test only four times and I have never taken the TOEIC L\&R." The other interviewees also referred to their lack of experience. If they had taken the TOEIC L\&R and achieved a high score, then they might feel that they had enriched their vocabulary.

As for Question 3, they found it useful to do some sort of preparation for the TOEIC L\&R in class, and therefore they considered that taking TOEIC L\&R vocabulary tests would motivate them to learn English. They were not sure if their textbook was worth using in class. One interviewee said, "I am afraid I don't think I have learned anything new from the textbook so far." He felt that preparing for the TOEIC L\&R was more worthwhile than doing exercises in the textbook. The other interviewees also mentioned that doing exercises in the textbook seemed like reviewing what they had already learned in high school, and thus preparing for the TOEIC L\&R was far more useful.

However, regarding Question 4, they felt that they would fall asleep in class regardless of the contents of the class. The interviewees identified several reasons for falling asleep in class: they were tired, they stayed up late the previous night, or they just did not feel like doing anything. One interviewee said, "I cannot help feeling sleepy when I am asked to do a lot of listening activities although I am tired for whatever the reason."

As for time allocation, none of the interviewees were sure if engaging in two different types of activities in a 
90-minute class was helpful for them to concentrate better in class. I suspected that using the first 20 minutes for something different from their textbook was more helpful for them to concentrate than using the full 90 minutes for the textbook only. However, none of the three interviewees gave a definite answer to this question. They just said, "I'm not sure" or "Could be." In fact, none of them stated that 90 minutes was too long for them to concentrate. Regarding this, one interviewee said, "Indeed 90 minutes is long, but I might be able to concentrate for 90 minutes, although I'm not sure." As far as the participants in this study were concerned, the length of class might not be directly related to falling asleep in class.

\section{Conclusion}

Falling asleep in class is a common phenomenon in EFL classes among Japanese university students. To find possible solutions to this problem, this study focused on motivation as a way to prevent students from falling asleep in English class. The findings of this study suggested that the answer to the first research question, "Does taking a vocabulary test at the beginning of class increase students' motivation?", was affirmative. After the experiment, $73.9 \%$ of the participants said they thought taking the TOEIC L\&R vocabulary test had increased their motivation. In addition, the focus group interview and follow-up survey revealed that all the participants preferred to take the test at the beginning of class. Participants in the focus group and semi-structured interviews said that if they had taken the test in the middle or near the end of class, they would have been so worried about the test that they would not have been able to concentrate. However, the findings also suggested that the answer to the second research question, "If so, does it also help prevent students from falling asleep in class?", was negative. The follow-up survey revealed that only $8.7 \%$ of the participants thought taking the TOEIC L\&R vocabulary test was helpful in preventing them from falling asleep in class, while $91.3 \%$ were not sure whether it was helpful or not.

This study found that students tended to consider preparing for the TOEIC L\&R to be more worthwhile than doing exercises in their textbook. The textbook consisted of general topics, with exercises that were similar to what they had done in high school. Therefore, doing some sort of preparation for the TOEIC L\&R would motivate students to learn English. However, the findings of this study also indicated that students would still fall asleep in class even if they felt motivated to learn English. Falling asleep in class is not only due to a lack of motivation but also due to other factors, which was confirmed by the follow-up survey. The results revealed that some of the participants considered that falling asleep in class was related to factors such as tiredness.

The results of this study were consistent with the findings of several previous studies on university students' daytime sleepiness. Some of the participants in this study suggested that their sleepiness in class resulted from their daily life habits. In the post-questionnaire, there was an opinion "I don't think falling asleep in class has anything to do with taking a test or something like that." One participant in the semi-structured interviews said, "I cannot help feeling sleepy when I am asked to do a lot of listening activities although I am tired for whatever the reason." Then, why were they too tired to stay awake in class? Hershner and Chervin (2014) pointed out that university students go to bed later and get up earlier than do high school students, and that they frequently use cellphones or computers before bed. These factors are part of their daily routine, which EFL teachers are not able to influence. On the other hand, attending a longer class did not seem to be related to falling asleep in class. I hypothesized that dividing a 90-minute class into 20 minutes for the test and the remaining 70 minutes for the textbook would help the students to concentrate on class activities, as it would be easier for them to concentrate on activities for a shorter period of time. However, none of the participants mentioned this time allocation, although they said that taking a test at the beginning of class was more helpful for them to concentrate on class activities than taking the test in the middle or near the end of class.

The findings of this study revealed that university students can be motivated to learn English if they are preparing for the TOEIC L\&R in EFL classes. The results seem promising for English education at Japanese universities. Recently, some Japanese universities, both national and private, have started to include the TOEIC L\&R as graduation requirements (The Institute for International Business Communication, 2016). Those who cannot achieve a certain score on the TOEIC L\&R cannot graduate from those universities. Required scores differ depending on which university or department the students are enrolled in. Some universities or departments require a score of 730, whereas others only require a score of 400 . There are, of course, pros and cons associated with setting such requirements at universities. Regarding the cons, such requirements are likely to result in students who are not good at English failing. Generally, it is not difficult for students to graduate from Japanese universities if they attend class regularly and memorize what they learn in class by taking notes. Professors usually make final exams easy enough for their students to pass their courses. However, achieving a high score on a high-stakes test is different. There have indeed been students who have failed to graduate from university simply because they did not achieve the minimum 
required score on the TOEIC L\&R. In such cases, universities give the students make-up lessons to help them achieve the minimum required score. However, this is a large burden on students as well as universities, and more importantly, it is possible that they still will not be able to achieve the required score even after taking the make-up lessons. Regarding the pros, requiring a certain TOEIC L\&R score means setting a clear goal for learning English, which is likely to motivate students. If students' English proficiency levels advance enough by the time they graduate, professors can give lectures, hold seminars, or conduct experiments in English at graduate school. They can introduce "English as a Medium of Instruction," which MEXT has advocated. The results of this study confirmed that setting such a clear goal is likely to motivate students to learn English in university. They might fall asleep in class even if they are motivated, but EFL teachers cannot address the sleepiness resulting from students' daily routine. It would likely be more helpful for students to receive mentoring to resolve such problems stemming from their personal lives. As $\mathrm{Lu}$ et al. (2011) suggested, what EFL teachers can do to reduce the falling asleep in class phenomenon is cultivate students' study interests or implement teaching reforms.

Several limitations of the present study should be mentioned. First, the experiment lasted only four weeks. This is a very short period of time, and thus different results might have emerged if the experiment had been conducted for longer. It would be interesting to investigate students' motivation after having them take the TOEIC L\&R and see their scores. Participants in this study said that they were not sure whether they had enriched their vocabulary by taking the TOEIC L\&R vocabulary tests, because they had not actually taken the TOEIC L\&R yet. If they could attain a desired score, this would be a sort of "reward" for their efforts. This would improve the students' satisfaction levels, since Gopang et al. (2015) included "provision of some rewards (prize, appreciation)" in their suggested solutions for student dissatisfaction (p. 143). Second, only 23 students participated in this study. It is thus necessary to examine a larger number of students to verify its results. It is also important to investigate various types of students. Participants in this study were students from the engineering department, and $87 \%$ of them were male and $13 \%$ female. It is worth investigating students from other departments where a majority of students are female. In addition, participants in this study were aged 18 to 20, which means that they came directly from high school. Such students might be different from those who once held a job and then entered university. From my experience, I would say that students who come directly from high school are likely to be interested in getting a job after graduation although students who once had a job tend to have different interests. Finally, the participants in this study had the same level of English proficiency, which was generally higher than that of other first-year students. It would thus be interesting to compare the responses of students with different English proficiency levels. For example, it should be noted that most of the participants achieved nearly full marks every time they took the vocabulary test. There were 15 vocabulary items on each test, and all the participants correctly wrote down the meanings of 13 to 15 items every time they took the test. Their level of English proficiency was thus high enough to prepare for the TOEIC L\&R. Therefore, the results of this study might differ if participants had lower English proficiency levels.

One issue, however, remains unresolved. This study did not draw any conclusions regarding the effect of a 90-minute class on the falling asleep in class phenomenon. It is natural to assume that dividing the 90 minutes into two sessions would be helpful for them to concentrate on each activity, as it is generally easier to concentrate for a shorter period of time. However, the participants in this study did not mention anything about the length of the class. One of the suggestions made by Lu et al. (2011) to address the problem of falling asleep in class was implementing "teaching reforms" (p. 508). Thus, it remains to be determined whether having students engage in different sorts of activities in a 90-minute class would be an effective strategy for improving student motivation. This is a topic that should be explored in future research.

\section{References}

Boo, Z., Dörnyei, Z., \& Ryan, S. (2015). L2 motivation research 2005-2014: Understanding a publication surge and a changing landscape. System, 55, 145-157. https://doi.org/10.1016/j.system.2015.10.006

Chi, M. T. H. (1997). Quantifying qualitative analysis of verbal data: A practical guide. The Journal of the Learning Sciences, 6(3), 271-315. https://doi.org/10.1207/s15327809j1s0603_1

de Souza, J. C., de Sousa, I. C., Maia, A. L., \& de Azevedo, C. M. (2012). Sleep patterns of teachers and adolescents who attend school in the morning. Biological Rhythm Research, 43(1), 65-72. https://doi.org/10.1080/09291016. 2011.638156

Dearden, J. (2014). English as a medium of instruction - a growing global phenomenon. London: British Council. Retrieved from https://www.britishcouncil.org/sites/default/files/e484_emi_-_cover_option_3_final_web.pdf

Gopang, I. B., Soomro, A. F., \& Bughio, F. A. (2015). Increasing motivation at university level: A paradigm of action 
research. Journal of Language Teaching and Research, 6(1), 140-146. http://dx.doi.org/10.17507/jltr.0601.17

Hershner, S. D., \& Chervin, R. D. (2014). Causes and consequences of sleepiness among college students. Nature and Science of Sleep, 6, 73-84. https://doi.org/10.2147/NSS.S62907

Lu, J., Fang, G. E., Shen, S. J., Wang, Y., \& Sun, Q. (2011). A questionnaire survey on sleeping in class phenomenon among Chinese medical undergraduates. Medical Teacher, 33(6), 508.

Ministry of Education, Culture, Sports, Science and Technology (2009). Higher Education in Japan. Retrieved from http://www.mext.go.jp/en/policy/education/highered/title03/detail03/_icsFiles/afieldfile/2012/06/19/1302653_ 1.pdf

Oginska, H., \& Pokorski, J. (2006). Fatigue and mood correlates of sleep length in three age-social groups: School children, students, and employees. Chronobiology International, 23(6), 1317-1328. https://www.tandfonline. com/doi/full/10.1080/07420520601089349

Rose, H., \& McKinley, J. (2018). Japan's English-medium instruction initiatives and the globalization of higher education. Higher Education, 75(1), 111-129. https://doi.org/10.1007/s10734-017-0125-1

The Institute for International Business Communication. (2007). Trends Survey of TOEIC L\&R Utilization 2007. Retrieved from http://www.iibc-global.org/library/default/english/lr/about/pdf/TOEIC_Utilization_2007.pdf

The Institute for International Business Communication. (2016). TOEIC, TOEIC S\&W. Retrieved from http://www. mext.go.jp/b_menu/shingi/chousa/shotou/117/shiryo/_icsFiles/afieldfile/2016/05/24/1368985_14_1.pdf

Turner, J., \& Paris, S. G. (1995). How literacy tasks influence children's motivation for literacy. The Reading Teacher, 48(8), 662-673. Retrieved from https://chelseehook.files.wordpress.com/2012/02/how-literacy-tasks-influence -childrens-motivation-for-literacy.pdf

Waninge, F., Dörnyei, Z., \& de Bot, K. (2014). Motivational dynamics in language learning: Change, stability, and context. Modern Language Journal, 98(3), 704-723. https://doi.org/10.1111/modl.12118 